\title{
Kesalahan Penulisan Kata Bahasa Indonesia Pada Kain Rentang dan Papan Iklan di Tempat Umum
}

\author{
Muji Endah Palupi
}

Akademi Bahasa Asing BSI Jakarta

muji.mji@bsi.ac.id

\section{Cara Sitasi:}

Palupi, M. E. (2018). Kesalahan Penulisan Kata Bahasa Indonesia Pada Kain Rentang dan Papan Iklan di Tempat Umum. Wanastra, 10(2), 13-20.

\begin{abstract}
Error writing is the crucial thing that found in the public places, especially on the banner and billboard. Sometimes, it has been written wrongly. It is known that Indonesian has a rich peculiar language that must be explored. People around it view the ad or advertisement; they will assess the ad internally and externally. It will be seen the professionalism of the ad maker. Badan Bahasa (Language Board) of Kemdikbud RI, has launched the print book of PUEBI on its website freely, it depends on the ad maker to revise the Indonesian using on the ad correctly and esthetically. The objective this research is to investigate the error writing of ad and its professionalism abuse on the banner and billboard at the public places. This research is using a descriptive method; the writer is to investigate and to analyze the error writing in Indonesian of ad on the banner and billboard. The output of this research is expected to be a reference to the next researcher that wants to explore error-writing research of ad or another peculiar object.
\end{abstract}

Keywords: Error Writing, Ad, Indonesian, Banner And Billboard

\section{PENDAHULUAN}

Saat ini banyak produsen atau pemilik usaha ingin memasarkan produk atau jasa mereka lewat berbagai media. Bisa lewat media cetak, elektronik, atau yang saat ini lewat media sosial. Sebut saja satu nama makanan cepat saji asal Amerika yang telah mendunia, Mcdonald produknya dapat ditemukan di setiap negara. Dari anak kecil sampai orang dewasa menyukai makanan cepat saji tersebut. Di sisi lain terdapat pula, penyedia layanan telekomunikasi (provider) yang sangat gencar memasarkan produk unggulannya untuk menarik konsumen. Seperti biasanya, mereka mencari media efektif agar dapat terlihat dan terpantau orang.

Media efektif yang dimaksud adalah media yang dapat dijangkau penglihatan orang, sehingga mereka segera mengetahui produk yang akan dipasarkan penyedia tersebut. Media elektronik memang cukup sangat efektif untuk mereka memasarkan produk, tapi kita semua tahu bahwa setiap orang pasti sibuk dengan kegiatannya masing-masing. tentunya mereka tidak selalu mendengarkan radio, atau menonton televisi. Media dalam kamus besar bahasa Indonesia edisi ke lima, yaitu alat (sarana) komunikasi seperti koran, majalah, radio, televisi, film, poster, dan spanduk. Jelas bahwa media tersebut terbagi menjadi cetak, elektronik, dan pajang.
Berbicara media pajang, dalam hal ini poster, spanduk, dan papan, sering kita temui di tempat umum. Seperti halnya jalan raya, kampus, pasar, ruko dan tempat umum lainnya. Isi dari iklan media tersebut, penyedia semaksimal mungkin memuat isi yang persuafif, mudah di mengerti, dan pastinya terjangkau. Permainan kata yang ciptakan oleh copywriter (penulis konten iklan) harus sempurna, tidak ada keterpaksaan, dan cukup berterima. Diperlukan kreativitas dan profesionalitas tinggi untuk menciptakan konten yang bermutu pada iklan tersebut, agar tidak dijadikan bahan rundungan jika iklan terpasang.

Berbicara konten atau isi iklan pasti menggunakan bahasa, baik asing atau pun Indonesia. Penulis yang bijak tentu saja memperhatikan diksi pada iklan tersebut. Diksi bahasa Indonesia disesuaikan dengan pembaca sebagai sasaran. Dari kasus di lapangan, banyak terjadi kesalahan penulisan kata mau pun isi iklan. terutama serapan bahasa asing, dalam hal ini Inggris ke bahasa Indonesia. Begitu pula bahasa Indonesia, sebagai bahasa persatuan bangsa Indonesia yang dirakit oleh pemuda dari berbagai belahan bumi pertiwi sembilan puluh tahun yang lalu. Semestinya kesalahan tersebut dapat dihindari atau terdeteksi sedari dini. Iklan yang dipajang, pasti memiliki kepala atau judul iklan dengan berbagai latar belakang.

Kesalahan penulisan tersebut sebenarnya dapat diminimalisir dengan pengetahuan bahasa yang 
cukup baik. Penulisan kata bahasa Indonesia yang salah, dapat menimbulkan multi tafsir oleh pembacanya, bahkan bias dicemooh, apakah penulis atau pembuat iklan tersebut professional atau tidak. Iklan yang baik yaitu menggunakan bahasa yang lugas, bersifat sugestif, bias juga disertai gambar, serta tidak menyinggung iklan lain.

Terkadang pembuat iklan tidak mempedulikan judul iklan tersebut. Padahal itu penting bagi pembaca iklan yang melihat. Contoh kesalahan penulisan kata pada iklan di jalan tertulis "Terima Juwal Beli Barang Rongsok". Dalam judul iklan tersebut tedapat kata "juwal" dan "rongsok", kedua kata tersebut sudah menyalahi tulisan bahasa Indonesia yang baik dan benar. Kata "juwal" semetinya ditulis "jual" tanpa penambahan huruf "w", dan kata "rongsok" semestinya ditulis "rongsokan", karena rongsok termasuk adjektiva atau kata sifat, dan rongsokan adalah termasuk ke dalam nomina atau kata benda. Di jalan, terkadang juga kita temukan kata resapan asing salah, seperti kata "photocopy". Kata ini terkadang sering ditulis "potocopy", "fotocopy", atau "photokopi". Menurut KBBI V (Kamus Besar Bahasa Indonesia versi kelima, tulisan yang benar adalah "fotokopi", hasil resapan bahasa Inggris ke dalam bahasa Indonesia.

Antara iklan dan bahasa yang dipakai untuk mengisi kontennya, harus ditulis dengan efektif, tidak ada kata eksegerasi atau kata-kata yang berlebihan. Bahasa Indonesia sejatinya memiliki khazanah perbendaharaan kata yang cukup kaya. Ditambah lagi dengan serapan-serapan bahasa asing, daerah, melayu, dan sansekerta. Dahulu Indonesia pernah dijajah Belanda, tidak dapat dipungkiri banyak sejarah yang ditinggalkan termasuk dari bahasa. Bahasa Inggris juga memainkan peranan penting atas perkembangan bahasa Indonesia. Serta bahasabahasa lain yang juga mempengaruhi bahasa Indonesia.

Bahasa Indonesia memiliki peranan penting atas perkembangan bahasa di dunia. Saat ini bahasa Indonesia menjadi kurikulum yang dipelajari di benua lain. Contoh di Australia, bahasa Indonesia masuk ke dalam kurikulum yang di pelajari di negara itu. Sehingga bangsa Indonesia perlu bangga, karena bahasanya dipelajari di benua lain. Berbeda dengan negara tetangga, bahasa Inggris menjadi 4 bahasa resmi kedua. Bahasa Melayu yang mereka gunakan sangat berbeda dengan bahasa Indonesia. Jadi bangsa Indonesia patut berbangga, karena bahasa Indonesia mempunyai integritas di negara lain.

Terpadunya antara bahasa Indonesia yang sering dipakai dalam iklan. Penulis tertarik untuk membahasnya di dalam penelitian ini. Di mana, penulis menemuka satu hal yang ganjil pada iklan yang terpajang di kain rentang dan papan iklan di tempat umum. Di sana banyak terjadi praktik kesalahan dalam pemakaian bahasa Indonesia. Kesalahan penulisan tersebut perlu dibenahi, agar tidak terjadi fosilisasi kesalahan yang mengakar hingga berlarut-larut.

Maka dari itu, penulis fokus pada kesalahan penulisan kata bahasa Indonesia. Sehingga didapatkan jawaban terjadinya kesalahan demi kesalahan penulisan kata bahasa Indonesia, dan bias dikatakan kemunduran berbahasa Indonesia. Berikut pertanyaan dalam penelitian ini:

1. Kesalahan penulisan kata apa saja yang biasa ditemukan di tempat umum?

2. Apa yang menyebabkan terjadinya kesalahan penulisan kata di tempat umum?

\section{METODOLOGI PENELITIAN}

Penelitian ini telah lama dilakukan, tetapi penulis ingin menambahkan sesuatu yang unik dari penelitian sebelumnya, dengan menghadirkan beberapa sumber:

\subsection{Pengertian Kata dalam Bahasa Indonesia}

Kata merupakan unit bahasa yang mengandung arti dan terdiri dari satu atau lebih morfem. Umumnya terdiri dari akar kata tanpa atau dengan beberapa afiks. Kata dikombinasikan untuk membentuk frase, klausa, atau kalimat. Dalam Kamus Besar Bahasa Indonesia (KBBI) edisi kelima, disebutkan bahwa kata merupakan:

1. 1. Unsur bahasa yang diucapkan atau dituliskan yang merupakan perwujudan kesatuan perasaan dan pikiran yang dapat digunakan dalam berbahasa

2. 2. Ujar; bicara

3. 3. Morfem atau kombinasi morfem yang oleh bahasawan dianggap sebagai satuan terkecil yang dapat diujarkan sebagai bentuk yang bebas

4. Satuan bahasa yang dapat berdiri sendiri, terjadi dari morfem tunggal (misalnya batu, rumah, datang) atau gabungan morfem (misalnya pejuang, pancasila, mahakuasa)

Berdasarkan bentuk, dapat diklasifikasikan ke dalam empat kata: kata dasar, kata turunan, kata ulang, dan kata majemuk. Kata dasar adalah kata yang menjadi dasar bagi pembentukan sebuah kata turunan atau kata-kata berimbuhan. Mengubah derivatif kata karena membubuhkan atau imbuhan baik di awal 
(prefix atau awalan), tengah (infiks atau sisipan), atau akhir (akhiran atau sufiks) kata-kata.

Kata adalah dasar dari kata atau atas dasar pengalaman perulangan bentuk semua atau bagian dari senyawa sementara adalah kombinasi dari beberapa kata-kata dasar yang berbeda untuk membentuk makna baru. Dalam tata bahasa Indonesia standar, dalam kelas kata dibagi menjadi tujuh kategori, yaitu:

1. Kata benda (noun) ; nama-nama orang, tempat, atau semua benda dan semua dibendakan, seperti buku, kuda.

2. Kata kerja (verb) ; kata yang menunjukkan tindakan atau rasa dinamis, misalnya baca, lari: Verba transitif (membunuh), Kerja kerja intransitif (almarhum), Pelengkap (menikah)

3. Kata sifat (adjective) ; sebuah kata yang menggambarkan kata benda, misalnya keras, cepat.

4. Kata keterangan (adverbia) ; kata-kata yang bersaksi kata tersebut tidak kata benda, seperti sekarang, agak.

5. Kata ganti (posesitive) ; kata pengganti kata benda, misalnya ia, itu: Yang pertama (kami), Orang kedua (Anda), Orang ketiga (mereka), Kata ganti posesif (itu), Kata ganti penunjuk (ini, itu)

6. Jumlah kata (numeral) ; mengatakan bahwa jumlah menyatakan benda atau hal-hal atau menunjukkan pesanan mereka berturut-turut, misalnya, satu, dua : Angka kardinal (dua belas),Nomor seri (dua belas) vf

7. Mengatakan tugas di luar kata-kata baik alih peran berdasarkan dapat dibagi menjadi lima sub kelompok : prepocition (kata depan) (contoh: dari), conjunction (hubungannya) coordinationi conjunction (dan), konjungsi bawahan (karena), artikula (kata sandang) (contoh: si) - Umum dalam bahasa Eropa (seperti), menangis (menangis) (contoh: wow, wow), dan partikel.

Dengan memahami kata dalam bahasa Indonesia sepenuhnya. Maka orang akan memiliki pedoman yang jelas dalam membuat suatu karya tulis, baik utuk keperluan akademik ataupun non-akademik. Terlebih lagi Badan Bahasa Kemdikbud RI juga telah memberikan akses secara percuma kepada masyarakat untuk mengunduh PUEBI versi cetak berformat PDF, dan seharusnya itu dimanfaatkan sebaik-baiknya.

\subsection{Definisi Iklan dalam Media}

Iklan adalah segala bentuk presentasi non-pribadi dan promosi gagasan, barang atau jasa oleh sponsor tertentu yang harus dibayar (Kotler (2005:277). Selain itu, bahwa iklan merupakan salah satu bentuk promosi yang paling banyak digunakan perusahaan dalam mempromosikan produknya (Tjiptono, 2008:225). Dan iklan adalah segala bentuk penyajian informasi dan promosi secara tidak langsung yang dilakukan oleh sponsor untuk menawarkan ide, barang atau jasa (Machfoedz, 2010:139).

Dari pengertian di atas, maka dapat disimpulkan bahwa iklan merupakan suatu bentuk komunikasi baik lewat media massa, TV, radio, surat kabar, majalah dan sebagainya yang bertujuan untuk mempengaruhi konsumen untuk bertindak terhadap produk dan jasa yang di tawarkan. Pada dasarnya iklan merupakan sarana komunikasi yang digunakan komunikator dalam hal ini perusahaan atau produsen untuk menyampaikan informasi tentang barang atau jasa kepada publik, khususnya pelanggannya melalui suatu media massa. Selain itu, semua iklan dibuat dengan tujuan yang sama yaitu untuk memberi informasi dan membujuk para konsumen untuk mencoba atau mengikuti apa yang ada di iklan tersebut, dapat berupa aktivitas mengkonsumsi produk dan jasa yang ditawarkan.

\section{PEMBAHASAN}

Pada penelitian ini, penulis menggunakan metode deskriptif kualitatif. Obyek penelitian ini yaitu kain rentang (spanduk) dan papan iklan di tempat umum. Selain itu, penulis juga mencari rujukan lain untuk mendukung penelitian ini, seperti riset perpustakaan dan mencari data berselancar di dunia maya. Berikut pembahasan dalam penelitian ini:

\section{Kesalahan Penulisan Kata yang Biasa Ditemukan di Tempat Umum}

Kesalahan penulisan kata bias saja terjadi kapan pun, disadari atau tidak, itu memang benar-benar terjadi di tempat umum. Berikut kesalahan penulisan kata yang biasa ditemukan di tempat umum:

\section{a. Penulisan Kata Baku dan Tidak Baku dalam Bahasa Indonesia}

Berikut penulisan kata baku dan tidak baku dalam bahasa Indonesia yang biasa ditemukan di tempat umum: 


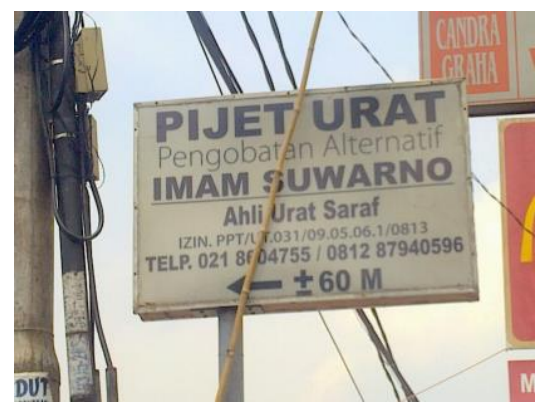

Gambar 1. Kata Tidak Baku

Tabel 1. Kata Tidak Baku dan Baku

\begin{tabular}{c|c}
\hline \multicolumn{1}{c|}{ Tidak Baku } & Baku \\
\hline $\begin{array}{l}\text { Pijet urat, pengobatan } \\
\text { alternatif }\end{array}$ & Pijat \\
\hline
\end{tabular}

Pada penulisan ini, kata "pijet" merupakan kata tidak baku dari kata "pijat". Dalam iklan tersebut mestinya ditulis "Terima Pelayanan Pijat dan Praktik Pengobatan Alternatif'. Dengan perbaikan dan penambahan kata tersebut, pelanggan yang datang dapat lebih percaya dengan pelayanan yang diberikan.

Ketidak-bakuan pada kata di atas menunjukkan bahwa pembuat iklan tersebut tidak paham betul dengan penggunaan bahasa Indonesia yang baik dan benar. Papan iklan ini banyak ditemukan di jalan umum, banyak orang yang tidak peduli akan hal ini, tetapi untuk pemerhati bahasa ini merupakan hal yang memperihatinkan. Semoga saja pembuat papan iklan tersebut segera membetulkannya.

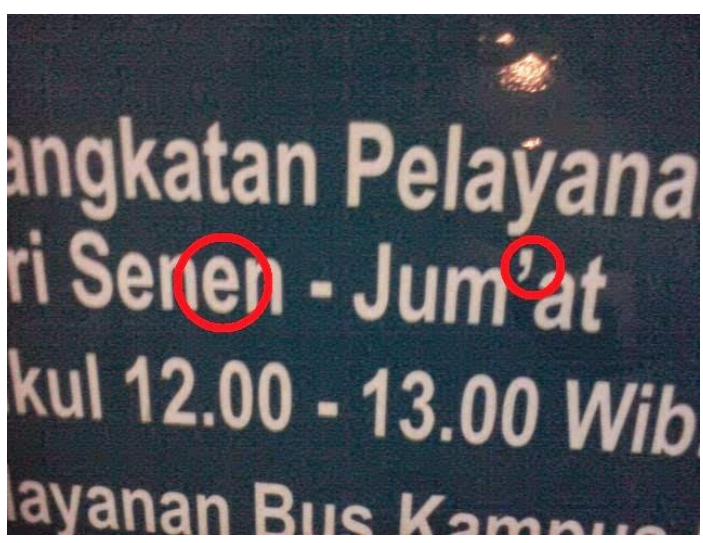

Gambar 2. Kata Tidak Baku
Tabel 2. Kata Tidak Baku dan Baku

\begin{tabular}{l|l}
\hline \multicolumn{1}{c|}{ Tidak Baku } & \multicolumn{1}{c}{ Baku } \\
\hline Praktek dokter & Praktik \\
$\begin{array}{l}\text { Setiap Hari Senen dan } \\
\text { Jum'at }\end{array}$ & Senin \\
& Jumat \\
\hline
\end{tabular}

Pemakaian kata "praktek, Senen, dan Jum'at" merupakan kata tidak baku dari kata "praktik, Senin, dan Jumat". Sebagaimana yang dimuat dalam buku PUEBI, bahwa kata-kata tersebut mesti ditulis baku. Sebab dengan penulisan kata-kata yang benar, niscaya pasien yang akan datang ke praktik dokter akan semakin percaya, bahwa dokter itu tidak hanya mahir dalam medis, tetapi juga mahir dalam berbahasa.

Hal itu merupakan kelebihan bagi dokter itu, karena seperti yang telah dipaparkan sebelumnya, bahwa bahasa Indonesia sebenarnya mudah dipelajari, sebab ini adalah bahasa resmi bangsa Indonesia, tetapi semua itu berpulang kepada si empunya urusan yang mengiklankan jasanya untuk orang lain. Jasa yang ditawarkan semestinya sesuai yang tertulis di papan iklan, kepercayaan konsumen menjadi titik awal majunya suatu usaha yang dilakukan oleh pembuat iklan.

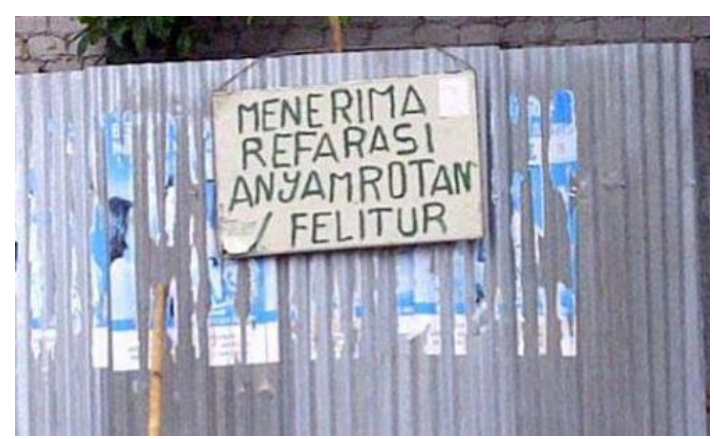

Gambar 3. Kata Tidak Baku

Tabel 3. Kata Tidak Baku dan Baku

\begin{tabular}{c|l}
\hline \multicolumn{1}{c|}{ Tidak Baku } & \multicolumn{1}{|c}{ Baku } \\
\hline $\begin{array}{l}\text { Menerima refarasi } \\
\text { anyam rotan felitur }\end{array}$ & Reparasi \\
& Pelitur \\
& \\
\hline
\end{tabular}


Dari tabel di atas, terlihat kata "refarasi, dan felitur" merupakan kata tidak baku dari kata "reparasi, dan pelitur". Dapat dipastikan pembuat iklan jasa tersebut berasal dari daerah Jawa Barat. Di mana, huruf " $p$ " diucap "f" dan huruf "f" dibaca " $p$ ". Lantas, mestinya papan iklan tersebut merujuk pemakaian kata yang baik dan benar, sebagaimana yang terdapat dalam KBBI edisi terbaru serta PUEBI sebagai pedoman berbahasa Indonesia.

Dalam kultur bahasa daerah, tepatnya dalam bahasa Sunda, huruf "p" dilafal " $f$ " begitu sebaliknya huruf "f" dilafal "p", contoh kata "fitnah" diucap "pitnah", lalu kata "pendaftaran" diucap "fendaptaran". Mungkin itu beberapa kata yang ditemukan dalam kultur bahasa Sunda. Tetapi selama pelafalan dan pengucapan tersebut mengandung makna jelas dalam bahasa Indonesia, sudah pasti kata tersebut berterima.

\section{b. Penggabungan Kata dalam Bahasa Indonesia}

Berikut kekeliruan yang biasa terjadi dalam penggabungan kata dalam Bahasa Indonesia:

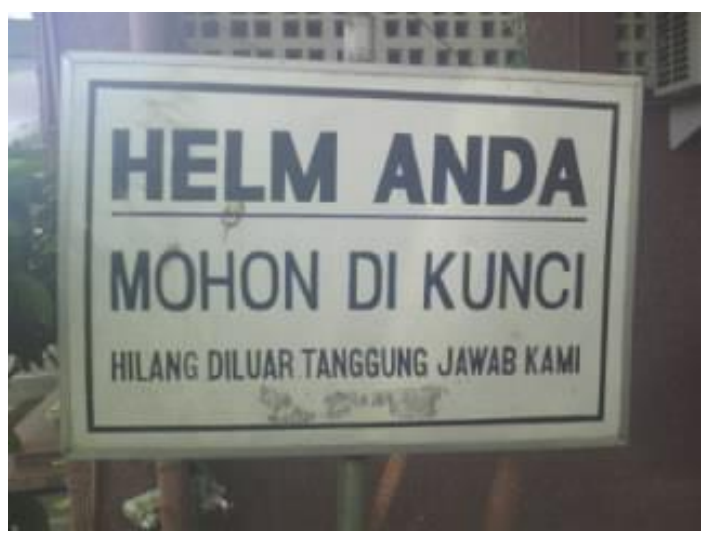

Gambar 4. Kata Tidak Baku

Tabel 4. Gabungan Kata

\begin{tabular}{l|l}
\hline \multicolumn{1}{c|}{ Salah } & \multicolumn{1}{c}{ Benar } \\
\hline $\begin{array}{l}\text { Helm anda mohon di } \\
\text { kunci, hilang diluar } \\
\text { tanggung jawab kami }\end{array}$ & dikunci \\
\hline
\end{tabular}

Pada konteks table di atas kata "kunci" merupakan verba atau kata kerja. Di mana preposisi atau kata depan harus digabung dengan verba sehingga menjadi bentuk kalimat pasif "dikunci". Lalu, kata "luar" bukanlah nomina, tetapi merupakan keterangan tempat, jadi harus terpisah dari preposisi, dan tidak terlihat sebagai verba yang dipasifkan.

Terkadang fungsi aktif dan pasif bisa saja tertukar dalam pemakaiannya. Dalam konteks kalimat aktif, subyek berperan aktif karena terdapat predikat, sedangkan dalam konteks kalimat pasif, subyek menjadi pelaku atas yang telah diperbuat. Perlu kecermatan dalam menempatkan fungsi kalimat tersebut. Serta, perlu diperhatikan pula di mana penggunaan kelas kata yang tepat dalam bahasa Indonesia.

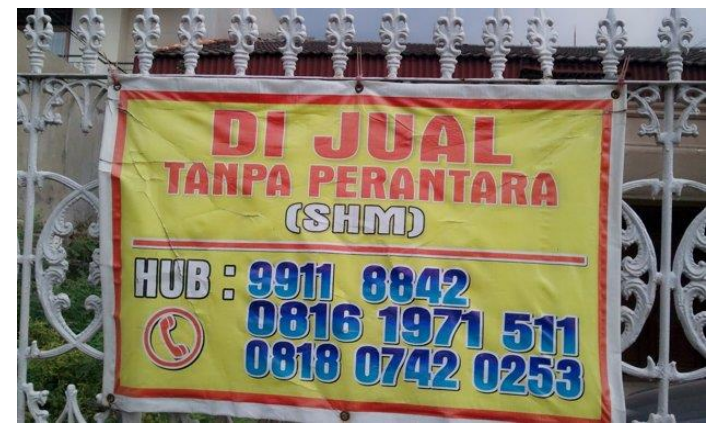

Gambar 5. Kata Tidak Baku

Tabel 5. Gabungan Kata

\begin{tabular}{l|l}
\hline \multicolumn{1}{c|}{ Salah } & \multicolumn{1}{c}{ Benar } \\
\hline $\begin{array}{l}\text { Rumah ini di jual tanpa } \\
\text { perantara }\end{array}$ & dijual \\
& \\
\hline
\end{tabular}

Kasus serupa ditemukan pada iklan jasa yang terdapat dalam tabel di atas. Preposisi terpisah dari verba, padahal yang benar harus tergabung, dan menjadi verba yang dipasifkan "dijual". Maka dari, pembuat iklan jasa ini harus baca PUEBI terlebih dahulu, sehingga bisa membuat iklan yang dapat dipahami dengan jelas dan tidak menimbulkan pertanyaan.

Hal ini ialah kebalikan dari kasus sebelumnya, di mana kesalahan penempatan preposisi. Hal ini bisa berakibat fatal bagi orang yang membacanya. Orang tersebut dapat mengalami multitafsir hingga ketaksaan, apakah itu termasuk nomina atau verba. Maka dari itu, pembuat iklan jasa harus betul-betul peka terhadap kelas kata yang digunakan agar orang bisa memahaminya dengan saksama. 


\section{PI LIARANG
MEROKOK
NO SMOKING}

Gambar 6. Kata Tidak Baku

Tabel 6. Gabungan Kata

\begin{tabular}{l|l}
\hline \multicolumn{1}{c|}{ Salah } & \multicolumn{1}{c}{ Benar } \\
\hline $\begin{array}{l}\text { Di larang merokok } \\
\text { dikawasan ini! }\end{array}$ & Dilarang \\
\hline
\end{tabular}

Kata dalam tabel di atas, biasanya ditemukan di area yang cukup steril dari api. Karena akan terjadi kebakan jika ada orang yang sengaja merokok atau menyalakan api. Kata "Di larang" atau dengan preposisi terpisah menjadi verba ini tidak sempurna, maka dari itu kata ini harus digabung antara preposisi dan verba agar menjadi pasif, sehingga orang tidak nampak taksa (ambigu) akan imbauan tersebut.

Dalam kasus ini lagi-lagi terjadi kerancuan pisah atau gabung dengan preposisi. Jelas, bahwa kata "larang" merupakan verba intransitive yang harus digabung dengan preposisi "di", sehingga menjadi pasif. Kata tersebut jelas memberitahu kepada orang atas imbauan yang harus dipatuhi oleh semua orang. Hal ini lumrah terjadi karena kealfaan pembuat imbauan, dan ini harus menjadi peringatan untuk pembuatnya agar lebih mengerti bahasa penggunaan bahasa Indonesia yang baik dan benar.

\section{Sebab Terjadinya Kesalahan Penulisan Kata di Tempat Umum}

Sebab musabab kesalahan penulisan mesti ditelesuriBerikut sebab terjadinya kesalahan penulisan kata di tempat umum:

\section{a. Kurang Pemahaman Tentang PUEBI (Pedoman Umum Ejaan Bahasa Indonesia}

Sebelumnya, dalam bahasa Indonesia terdapat pedoman Ejaan Yang Disempurnakan atau disingkat menjadi EYD. Pedoman ini diresmikan oleh Soeharto selaku Presiden Republik Indonesia saat itu pada HUT RI ke duapuluh tujuh, tanggal 17 Agustus 1972. EYD menjadi pedoman bagi seluruh rakyat Indonesia untuk keperluan penulisan secara akademik dengan bahasa Indonesia secara baik dan benar.

Seiring waktu berjalan, perkembangan bahasa Indonesia semakin luas dan kaya, maka pada tahun 2016 terbitlah PUEBI (Pedoman Umum Ejaan Bahasa Indonesia, berdasarkan Peraturan Menteri Pendidikan dan Kebudayaan Republik Indonesia Nomor 50 Tahun 2015 tanggal 26 November 2016. Pedoman ini menjadi rujukan yang telah diperbarui oleh Badan Bahasa Kemdikbud sebagai lembaga institusional yang berwenang untuk mengelola perkembangan bahasa di Indonesia.

Sebenarnya Badan Bahasa telah memberikan akses secara percuma, atau secara gratis kepada masyarakat umum untuk mengunduh berkas cetak PUEBI (Pedoman Umum Ejaan Bahasa Indonesia) dengan format pdf di halaman Badan Bahasa menjelaskan yaitu.

"http://badanbahasa.kemdikbud.go.id/lamanbahasa/s ites/default/files/PUEBI.pdf'.. Bahwa masyarakat hanya tinggal mengunduh lalu mencetaknya menjadi buku.

Dengan demikian masyarakat tidak lagi menjadi "buta" aturan akan pemakian bahasa yang baik dan benar, selanjutnya PUEBI benar-benar menjadi pedoman yang hakiki untuk membuat sebuah tulisan. Sebab produk ini merupakan peraturan menteri (permen) untuk setiap warga negara dalam penggunaan atau pemakaian bahasa Indonesia secara baik dan benar.

\section{b. Kurang Pemahaman Tentang Pembuatan Iklan Secara Profesional}

Iklan yang terpajang di tempat umum, menjadi sorotan setiap mata yang memandang. Orang akan menilai iklan tersebut secara internal maupun eksternal, maksudnya adalah orang akan menilai iklan itu dari segi bahasa secara internal, dan dari segi estetika secara eksternal. Dari penilaian itu iklan menjadi terhilat lebih estetis atau memilki nilai plus. Lalu masyarakat sebagai pengguna akan tertarik menggunakan jasa itu pastinya.

Maka dari itu pembuat jasa iklan mesti diberi pelatihan yang cukup. Sebenarnya ada kajian yang disebut dengan "copywriting” atau penulisan konten iklan. Dengan kajian ini diharapkan para pembuat iklan dapat memperhatikan penggunaan atau pemakaian bahasa Indonesia dengan baik dan benar. Sehingga iklan yang nantinya dipajang menjadi iklan terbaik dan laku. Karena pemilihan diksi serta 
strukur bahasanya jelass dan dapat diterima masyarakat umum.

\section{HASIL PEMBAHASAN}

1. Kesalahan penulisan kata pada tempat umum harus dihindari, sebab pembaca harus memahami tulisan tersebut jika tidak ingin dibuat bingung, sebenarnya pembuat tulisan tersebut paham atau tidak. Terlebih lagi, jika tulisan itu dipajang di kain rentang atau papan iklan. Dari judul iklan tersebut, pembaca akan menilai sejauh mana profesionalitas dari pembuatan tulisan iklan yang dipajang di tempat umum. Dan ini menjadi perhatian khusus untuk pembuat iklan atau ad maker.

2. .Dengan adanya PUEBI yang diterbitkan oleh Badan Bahasa Kemdikbud RI, pihak berwenang dalam pengelola bahasa, diharapkan dapat digunakan dengan sebagaimana mestinya, serta untuk menghidari kesalahan dan ketaksaan dalam berbahasa Indonesia, dan itu adalah nilai plus atau bargaining untuk pembuat iklan karena telah mengikuti aturan yang terdapat dalam PUEBI.

\section{KESIMPULAN}

Dengan demikian, jelas bahwa kata baku dan takbaku, kelas kata, penggabungan dan pemisahan preposisi dan verba dalam bahasa Indonesia harus benar-benar diperhatikan secara saksama, sebab ini sangat penting bagi pembuat iklan di kain rentang dan papan iklan di ditempat umum. Keterbatasan dalam penggunaan bahasa Indonesia bukan suatu halangan mendasar, sebab Badan Bahasa Kemendikbud dalam laman resminya. Penggguna umum dapat mengunduh secara bebas tanpa dipungut bayaran sepeser pun. Ini dimaksudkan untuk masyarakat dapat menggunakan bahasa Indonesia dengan baik dan benar.

Kesalahan penulisan di tempat umum memang lumrah terjadi di kalangan masyarakat. Tetapi apa salahnya jika mereka melakukan pratinjau tulisan yang akan diklankan. Pada waktu itu kita tahu dengan istilah Ejaan Yang Disempurnakan atau biasa disingkat EYD. Seiring waktu berjalan, banyak terjadi perkembangan lema baru yang ditemukan di masyarakat, hingga pada tahun 2015, Kemendikbud sebagai garda utama yang menggawangi bidang bahasa, terutama Badan Bahasa yang bertugas mengembangkan bahasa di Indonesia dan akhirnya merilis Pedoman Umum Ejaan Bahasa Indonesia atau PUEBI sebagai "kitab" acuan berbahasa Indonesia yang dan benar.

Dengan adanya PUEBI, niscaya kesalahan penggunaan bahasa Indonesia dapat terhindarkan dalam membuat iklan. Lalu konsumen atau pasien "tergoda" untuk memakai jasa yang ditawarkan dalam iklan. Kecakapan dalam membuat iklan sangat penting sekali, mengingat tulisan yang dibaca oleh orang pastinya berpengaruh terhadap nilai jual jasa yang dipasang dalam iklan. Dengan kecakapan ini dapat dipastikan bahwa iklan tersebut akan "laris manis" dan mempunyai daya jual yang bersaing di mata masyarakat.

\section{REFERENSI}

Chaer, Abdul. 2007. Linguistik Umum

Jakarta: Rineka Cipta.

Chaer, Abdul. 2011. Ragam Bahasa Ilmiah.

Jakarta: Rineka Cipta.

Keraf, Gorys. 2010. Diksi dan Gaya Bahasa.

Cet. Keduapuluh. Jakarta: Gramedia

Pustaka Utama.

Kotler etc, Philip. 2016. Marketing Management. New Jersey : Pearson Education Limited

Machfoedz, Mahmud. 2005. Pengantar

Pemasaran Modern. Yogyakarta:

UPP AMP YKPN Pengembang Pedoman Bahasa Indonesia

, Tim. 2016. Pedoman Umum Ejaan

Bahasa Indonesia. Jakarta: Badan

Pengembangan dan Pembinaan Bahasa . Kemdikbud RI

Tjiptono, Fandy. 2010. Strategi Pemasaran. Yogyakarta:Penerbit Andi

2016. Kamus Besar Bahasa Indonesia

Jakarta: Menteri Pendidikan dan Kebudayaan Republik Indonesia 


\section{PROFIL PENULIS}

Muji Endah Palupi, SS, M.Pd lahir di Jakarta Pada tahun 1973. Penulis memperoleh gelar Sarjana Sastra, Jurusan Bahasa dan Sastra Inggris di STIBA IEC pada tahun 2012 dan gelar Magister, Fakultas Pendidikan Bahasa Inggris di Universitas Indraprasta PGRI pada tahun 2015. Penulis bekerja sebagai Dosen Bahasa Inggris di ABA BSI dari tahun 2013 - sampai saat ini. Selain itu pekerjaan yang ditekuni sebagai konsultasi pelajaran Bahasa Inggris di Bimbingan Belajar, pengajar Bahasa Turki. Penulis aktif dalam seminar, workshop, kegiatan lain yang berkaitan dengan ilmu pendidikan. Penulis juga aktif di Polyglot Indonesia, Organisasi di bidang Ilmu Bahasa Asing dan Kebudayaan Asing Dunia. 